\title{
LA VIDA DE UN GÉNERO LITERARIO. LA BIOGRAFÍA FICTICIA Y SU RUTA ENTRE CONTINENTES: SCHWOB, BORGES, WILCOCK Y BOLAÑO
}

\author{
Kata Varju \\ Universidad Eötvös Loránd de Budapest \\ katavarju@gmail.com
}

RESUMEN: Tras examinar el ritmo en las obras de Roberto Bolaño y teniendo en cuenta la historia de la biografía apócrifa o ficticia, se puede establecer que la tradición fundada por Marcel Schwob tiene gran repercusión en la obra de varios escritores. El presente estudio intenta desvelar las características comunes de este género y su breve historia entre continentes.

PALABRAS CLAVE: biografía ficticia, vies imaginaires, biografemas, reescritura irónica

\begin{abstract}
If we study the rhythm in the works of Roberto Bolaño and we also consider the history of fictive biography, we can establish that the tradition founded by Marcel Schwob echoes in several texts of other writers. The present study tries to reveal the joint characteristics of the genre as well as its short transatlantic history.
\end{abstract}

KEYWORDS: fictive biography, vies imaginaires, biographemes, ironic rewriting

Pertenecer al grupo de los happy few, como lo denomina Borges, no es una tarea simple. Mi punto de partida era la voluntad de encontrar las bases del ritmo interior en la narrativa de Roberto Bolaño, pero basándome en sus textos, pronto llegué a los biografemas ${ }^{1}$ de Barthes, de donde se abrió un camino directo hacia el microgénero de la biografía apócrifa. Los escritores que han compartido la pasión de Marcel Schwob han creado un microuniverso, una literatura que queda excluida del canon literario oficial. La vidas imaginarias crean un grupo inquientante que no dan fácil acceso para el lector ni para el filólogo. A continuación intentaré desvelar las posibles causas de esta inquietud.

\section{Acerca de la escritura de Marcel Schwob}

Si hablamos sobre la biografía apócrifa, debemos comenzarlo con Marcel Schwob (1867-1905). Este escritor está rebelándose contra la tradición clásica de la biografía. En 1896 escribe Vies imaginaires (Vidas imaginarias) que contiene veintidós biografías ficticias. Sus héroes son dioses, poetas, asesinos y piratas. Sus fuentes son documentos difícilmente accesibles, como lo ha demonstrado Francisco García Jurado en su trabajo, donde detalla cuatro fuentes de la

\footnotetext{
${ }^{1}$ François Dosset menciona que las biografemas de Roland Barthes le recuerdan a los relatos de Marcel Schwob. (Dosset, 2007: 307) Barthes escribe así: "Si yo fuera escritor y estuviera muerto, me agradaría que mi vida se redujera mediante los cuidados de un biógrafo amistoso y desenvuelto a algunos detalles, a algunos gustos, a algunas inflexiones, digamos a algunos 'biografemas' cuya distinción y movilidad pudieran trasladarse fuera de todo destino y llegar a tocar, cómo átomos epicúreos, algún cuerpo futuro, destinado a la misma dispersión; en suma, una vida abierta en brecha, así como Proust supo escribir la suya en su obra" (Barthes, 1989: 11). En otro lugar sigue así: "La Fotografía me permite el accesso a un infra-saber; me proporciona una colección de objetos parciales y puede deleitar cierto fetichismo que hay en mí: pues hay 'yo' que ama el saber, que siente hacia él como un gusto amoroso. Del mismo modo, me gustan ciertos rasgos biográficos en la vida de un escritor me encantan igual que ciertas fotografías; a estos rasgos los he llamado 'biografemas'; la Fotografía es a la Historia lo que el biografema es a la biografía" (Barthes, 1977: 62).
} 
literatura latina: "Es muy llamativo el hecho de que Schwob se inspire en textos latinos para elaborar cuatro de sus vidas, como son las de Séptima, Lucrecio, Lesbia y Petronio" (2004: 118). María José Hernández Guerrero cita la frase de Genette para caracterizar la reescritura en las obras de Schwob: "Surge así lo que Genette (1982) denomina 'littérature au second degré, qui s'écrit en lisant"' (2007: 126). Marcel Schwob estaba convencido de que todo había sido escrito y de que él lo había leído todo, así nunca intentó disimular sus fuentes:

A finales del XIX eran muchos los escritores abrumados por siglos de producción escrita que habían ido agotando las fuentes de inspiración y que consideraban todas esas obras anteriores como un inmenso 'archivo' del que poder extraer 'documentación' con la que nutrirse y enriquecer sus propias obras. [...] Marcel Schwob constituye una de sus mejores exponentes, pues se sirve de la imitación de una manera consciente, deliberada, e incluso declarada. (Hernández Guerrero, 2007: 126)

Utiliza estos documentos como trasfondo y su imaginación modifica lo original, destaca otro elemento no expuesto en el texto original, añade otros personajes o modifica la historia. "La historia en estos relatos queda como mera referencia, como mera anécdota, y sirve de pretextos para desplegar con enorme libertad los temas y los personajes que le interesan" (Hernández Guerrero, 2007: 129). No obstante, esta relación de reescritura no es una imitación:

Sus textos se apropian, hibridan, distorsionan y recombinan los elementos ya existentes en la cultura, que acaban integrados en su producción y se prolongan a través de ella inscribiéndose en una línea trazada en la memoria colectiva, donde circulan libremente ecos y signos universales. Una literatura de imitación que, paradójicamente, mediante un elaborado proceso de reescritura, desemboca en la más completa originalidad. (Hernández Guerrero, 2007: 133)

En su producción literaria, utiliza solamente el relato o el poema en prosa. Aunque ha publicado sus obras primero en revistas, tras la recopilación de los textos sueltos en tomos, en los exordios de los mismos exige que sus textos sean leídos como novelas. Es verdad que sus relatos publicados en un tomo "poseen una unidad, un sentido, gracias a la orientación proporcionada en su introducción o a la existencia de un hilo conductor" (Hernández Guerrero, 2004a: 192). En su trabajo excelente, Hernández Guerrero intenta demostrar que Marcel Schwob no ha sido simbolista y que su trabajo es una puerta abierta de par en par hacia la novela impresionista:

Tal vez sea éste el rasgo distintivo de su legado, lo que diferencia su producción de otros autores que también publicaron conjuntos de relatos. A pesar del carácter fragmentario de su escritura, Schwob insiste en la presencia de un hilo conductor, que se manifiesta en la unidad expresamente sentida y justificada por el autor en prólogos y otros escritos a los que nos remiteremos para analizar esta forma original de composición. Los prólogos en concreto desempeñan un papel clave en la primeras producciones schwobianas. (Hernández Guerrero, 2004b: 192)

Schwob rompe con la narración tradicional, con la linearidad y la cronología, y exige de sus lectores una especie de capacidad sintética. Hablando sobre Vidas imaginarias afirma Hernández Guerrero: "Así pues, estas narraciones breves continúan el trazado narrativo en un principio y proponen al lector una síntesis de la historia del mundo en veintidós 'vidas' que renuevan la tradición literaria y suponen un nuevo peldaño en el proyecto schwobiano de narración fragmentaria" (Hernández Guerrero, 2004b: 197). El hilo conductor temático de este tomo es el par binario general/particular. La realidad aparece de manera fragmentada, a través del uso de la forma del relato breve, pero unidos en un tomo, estos fragmentos llegan a construir una obra de arte total: la fragmentación por tanto no aparece a nivel textual, sino en la forma.

Élodie Gaden propone la idea de fuerzas dobles que obran en estas vies de Schwob: una es centrípeta, constituida por la brevedad de la forma y otra esta centrífuga, que aparece a través 
de la imaginación que alimenta la narración (Gaden, 2005: s.p.). Modificando su postura podemos decir que la forma breve, el abandono de la narrativa clásica $\mathrm{y}$, en este caso, la subversión del género de la biografía constituyen la fuerza centrípeta, mientras los prólogos, el hilo conductor temático y el estilo unificador (ironía, pero con postura aparentemente neutral del narrador) dan la fuerza centrífuga. Aunque en la física elemental estas fuerzas no pueden existir al mismo tiempo, en la obra de Schwob sí coexisten, aunque creando tensiones por una parte entre la forma novelística y la forma breve del relato, y por otra, debido a su postura que descarta la biografía historiográfica y el naturalismo de su época. Y a través de esta tensión, Marcel Schwob es precursor de la denominada escritura moderna, propia de los siglos XX y XXI.

Todos los estudios mencionan la ironía como característica de las obras del autor - y también es una calidad primordial en las biografías apócrifas -. La ironía aparece en nivel textual en Vidas imaginarias, pero es más importante su manifestación a nivel extratextual, debido al puro hecho de la reescritura irónica del género historiográfico. Silvia Ragusa ha realizado un estudio donde trata exlusivamente los aspectos de la ironía textual. Como lo escribe en su ensayo, la ironía requiere informaciones de trasfondo:

Tanto Schwob como Borges poseen un vasto caudal de erudición, concibiendo la ironía - sutil - como una de las cosas más importantes de su literatura, en donde, por medio de ésta, el lector participa también en un juego de complicidades, ya que dar con el significado implícito depende, en gran medida, de los conocimientos del lector; de que éste sea capaz de interpretar las claves - la mayoría de las veces en tono de parodia - que el escritor le lanza. (Ragusa, 2008: s.p.)

Víctor Gustavo Zonana, hablando de varias obras de la biografía ficticia, resume así el uso de la ironía y del humor negro:

El humor, la ironía o el sarcasmo son recursos empleados para exorcizar y atenuar la manifestación del mal. Tales recursos, sin embargo, no desvanecen el efecto que provoca la aprehensión retrospectiva de los volúmenes estudiados. Cuando el lector culmina la lectura, percibe que la historia universal no revela la progresiva apoteosis del espíritu Absoluto, sino la de la infamia. Schwob, Borges y Wilcock se sirven de la transformación de un género historiográfico para presentar una crítica a la filosofía hegeliana de la historia. (2000: 686)

Es muy importante destacar que la ironía textual nunca se deriva de la postura del narrador, quedando esta neutral, "casi imparcial", sino son los actos de los protagonistas que revelan lo irónico a través de sus actos (Suárez Hernán y Macías Horas, 2013: 505-506).

En cuanto a la ironía extratextual, a mi parecer, más importante es la primera, que trataré en el apartado titulado "La biografía apócrifa del futuro".

Resumiendo, se puede decir que Marcel Schwob ha adelantado su época y ha introducido algunos principios que florecerán hasta hoy. El elemento más destacado de este cambio puede ser la síntesis: la lectura de sus obras requiere, en vez de deducción, inducción por parte del lector. Si aplicamos el razonamiento inductivo, nunca podemos llegar a un resultado absoluto. No obstante, el filósofo Bacon ha establecido este método como apto para la observación de la naturaleza. De acuerdo con este procedimiento lógico, durante la lectura no podemos formar opinión sobre el resultado, pero al acabar la novela, tenemos alguna idea sobre su significado global. Volveré a este punto más adelante.

\section{El arte de la biografía}

Para entender el microgénero creado por Marcel Schwob con la publicación de Vidas imaginarias en 1896, debemos seguir su prólogo de este tomo, que posteriormente se irá publicando con el título "El arte de la biografia". Hasta el presente, se trata del documento más valioso a la hora de acercarnos a este género. 
Primero, establece su postura en cuanto a la historiografía, y en vez de lo factual, implanta lo ficcional como característica destacada para este género: "La ciencia histórica nos deja en la incertidumbre con respecto a los individuos. Tan sólo nos revela los nudos por los que fueron ligados a las acciones generales" (Schwob, 2012: 83). "Por desgracia, los biógrafos han creído a menudo que eran historiadores, privándonos así de retratos admirables. Han supuesto que sólo la vida de los grandes hombres podía interesarnos. Pero el arte es ajeno a estas consideraciones" (Schwob, 2012: 91). Víctor Gustavo Zonana describe así esta característica: "En estas colecciones se ofrece un conjunto de biografías imaginarias elaboradas mediante la inversión de principios y rasgos que caracterizan a la biografía en cuanto subgénero historiográfico" (Zonana, 2000: 687).

El relato biográfico ya no se orienta ni a satisfacer el ansia de conocimiento, ni a provocar la imitación o la aversión. El desplazamiento del subgénero, de lo historiográfico a lo literario, determina que la biografía asuma los efectos de la ficción, del cuento. Entre ellos, provocar un entretenimiento. [...] Sin embargo, el tono sensacionalista, el humor, los juegos de piratas no suprimen la forma pesimista de entender la historia. Tal como se ha señalado, la inversión de la morfología heroica manifiesta un cambio cosmovisionario profundo. Un contexto que no da lugar al heroísmo, a la lucha por la consecución de un ideal noble, deja lugar al imperio del mal. Pero ya no concebido desde un horizonte religioso, [...] sino como imperio de la banalidad, del azar. (Zonana, 2000: 688)

Schwob establece la brevedad como otra característica necesaria del género, criticando la obra de Boswell: "Y si el libro de Boswell ocupara diez páginas sería la obra de arte esperada" (Schwob, 2012: 90). El escritor de biografías debe escoger lo individual, lo extraño, que mejor caracterice el sujeto:

El arte es lo contrario de las ideas generales, no describe sino lo individual, no desea más que lo único. [...] El arte del biógrafo consiste precisamente en la elección. No tiene que preocuparse por ser verdadero; debe crear dentro de un caos de rasgos humanos. Leibniz dijo que para hacer el mundo Dios escogió el mejor entre los posibles. El biógrafo, como una divinidad inferior, sabe escoger entre los posibles humanos aquel que es único. (Schwob, 2012: 83, 90-91)

El personaje elegido no debe estar conocido ni célebre, puesto que "[e]l arte del biógrafo consistiría en conferir idéntico valor a la vida de un pobre actor que a la vida de Shakespeare" (Schwob, 2012: 91). No obstante, el escritor debe incluir la síntesis de la época en su obra, como cuando añade una descripción de paisaje a una tabella original, en el cuento de "Séptima".

Manifiesta que la novela de aventuras será la forma del futuro, donde la aventura se refiere a una crisis exterior, donde predomina la acción sobre la descripción, que disturba la vida interior y, de esta manera, "la vida humana [es] concebida como una sucesión de aventuras, de lo que debe ocuparse el arte" (Schwob, 2012: 39). Sobre el estilo que el autor exige del futuro y de sí mismo, hay que afirmar que la característica más importante es la simplicidad y la construcción severa (Schwob, 2012: 75), y estas obras "[p]resentarán, a veces, la apariencia de fragmentos y, por lo tanto, se les deberá considerar como parte de un todo, ya que la crisis ha sido elegida como único objeto de respersentación artística" (Schwob, 2012: 69).

En su prólogo a Corazón doble establece su teoría de síntesis:

Resulta singular que en el tiempo en el que tanto se habla de síntesis nadie sepa llevarla a cabo. La síntesis no consiste en agrupar los elementos de una psicología individual, ni en reunir los detalles descriptivos de una línea ferroviaria, de una mina, de la Bolsa o del ejército.

Así entendida, la síntesis es enumeración. Y si el autor pretende extraer una idea general de las semejanzas que presentan los momentos de la serie, sólo estará haciendo una banal abstracción, ya se trate del amor de los salones, ya del corazón de París. La vida no se encuentra en lo general, sino en lo particular. El arte consiste en dar a lo particular la ilusión de lo general. 
[...] La ciencia busca lo general por lo necesario; el arte debe buscar lo general por lo contingente. Para la ciencia, el mundo está relacionado y determinado; para el arte, el mundo es discontinuo y libre. La ciencia descubre la generalidad extensiva; el arte debe hacer sentir la generalidad intensiva. Si el dominio de la ciencia es el determinismo, el dominio del arte es la libertad. (fragmentos selectos, Schwob, 2012: 70-72)

En cuanto a la síntesis, el autor declara su desilusión porque la ciencia de su época no ha podido sintetizar la totalidad de la vida. Como aparece en su charla con W. G. C. Byvanck, piensa lo mismo de la novela psicológica, que según él no puede describir a las personas. En vez de deducción, introduce un método de falso inducción, que se basa en intuir la totalidad. Es decir, después de leer los relatos breves ordenados en una novela, encabezados por un exordio orientador, el lector debe sintetizar la totalidad desde estos fragmentos bien ambientados, que siempre destacan algo extraño en el sentido bien conocido del bon mot: "Las ideas de los grandes hombres son el patrimonio común de la humanidad: en realidad, cada una de ellos no poseyó más que sus extravagancias" (Schwob, 2012: 84). Si la obra literaria es un organismo vivo que solamente deja intuir la totalidad de lo descrito, "la síntesis será la de un ser vivo" (Schwob, 2012: 73).

He mencionado el carácter desconcertante de las biografías imaginarias. Intuyo que es precisamente por el método narrativo anteriormente detallado que el lector quedará sin pistas frente al reto de descifrar los subyacente.

\section{Biografía apócrifa en diáspora}

La ruta entre continentes de la ficción biográfica comienza con Jorge Luis Borges, quien, para iniciar su marcha triunfal en el universo del relato, ha seleccionado precisamente este subgénero. Así escribe en su Biblioteca personal (1985) sobre Vidas imaginarias:

Para su escritura [Schwob] inventó un método curioso. Los protagonistas son reales; los hechos pueden ser fabulosos y no pocas veces fantásticos. El sabor peculiar de este volumen está en este vaivén.

En todas partes del mundo hay devotos de Marcel Schwob que constituyen pequeñas sociedades secretas. No buscó la fama; escribió deliberadamente para los happy few, para los menos. $[\ldots]$

Hacia 1935 escribí un libro candoroso que se llamaba Historia universal de la infamia. Una de sus muchas fuentes, no señalada aún por la crítica, fue este libro de Schwob. (Borges, 2005: 174)

Los relatos de Borges han sido publicados primero en el suplemento dominical de la revista Crítica en 1935. Borges afirma que los cuentos estaban destinados al consumo masivo, y por esto son "deliberadamente pintorescos". En el prólogo del tomo, señala a Stevenson y a Chesterton como fuentes, pero el nombre de Marcel Schwob ${ }^{2}$ queda excluído, mientras él es la influencia más relevante. Alude a los relatos del tomo como "ejercicios de prosa narrativa" (Borges, 2005: 7). También realiza una paráfrasis irónica en el exordio que evoca claramente el pensamiento schwobiano de que todo ha sido escrito ya: "Leer, por lo pronto, es una actividad posterior a la de escribir: más resignada, más civil, más intelectual" (Borges, 2005: 8). Jaime Alazraki afirma que "[l] o cierto es que esa primera colección prefigura al Borges más tardío" (1983: 247). Alazraki piensa que el relato de infamia es para "entretener al lector suspendiendo

\footnotetext{
${ }^{2}$ Suárez Hernán y Macías Horas mencionan que Borges ha conocido la obra de Schwob durante su estancia en Suiza. No obstante, se debe aclarar que la esposa de Schwob, Marguerite Moreno, se ha trasladado a Argentina en 1905, después de la muerte de Schwob, y allí trabajó como institutriz de Victoria Ocampo (Chirat, 2003: s.p.).
} 
sus criterios de bien y mal, convirtiendo actos viles en pretexto de carcajada y transformando lo abominable y condenable para nuestra civilidad en risible caricatura" (1983: 248).

Aunque Alazraki no menciona el nombre de Marcel Schwob, establece los rasgos más importantes de las biografías apócrifas: el relato como relectura; el comentario del narrador a su propio texto; la declaración de fuentes, apócrifas o reales; la serie de frases nominales; la historia enmarcada (1983: 251-252). También alude a un estilo de "farsa", "como si el estilo estuviera ya dictado desde los temas de estas historias" (Alazraki, 1983: 254) - o dictado precisamente por el precursor Marcel Schwob-.

Juan Rodolfo Wilcock (1919-1978), perteneciente al grupo Sur como poeta argentino, deja su país y se traslada a Italia para convertirse en narrador. Desde 1960 escribe en italiano. En 1972, publica su novela La sinagoga de los iconoclastas, que aparece en castellano en 1981. No incluye ningún prólogo, no alude a Schwob ni a Borges. Tan solo en una nota final menciona el libro del que ha extraído varias de sus historias. Roberto Bolaño elogia su obra de esta manera:

La sinagoga de los iconoclastas es uno de los mejores libros que se han escrito en este siglo. Su autor, Rodolfo Wilcock, es un escritor legendario. [...] La sinagoga de los iconoclastas, cuya primera edición italiana es de 1972, es sin duda uno de los libros más felices, más irreverentes, más humorísticos y corrosivos de este siglo. Deudor de Borges, de Alfonso Reyes y de Marcel Schwob, deudores éstos a su vez, a la manera de los espejos deformantes, de la prosa de los enciclopedistas, La sinagoga de los iconoclastas es una colección de biografías de inventores delirantes, aventureros, científicos y algún que otro artista. [...] Sus personajes, cuando son malos, son malos de tan buenos que son, y cuando son buenos son inconscientes y entonces son temibles, tan temibles, sin embargo, como todos los seres humanos. La prosa de Wilcock, metódica, siempre certera, discreta aunque trate temas escabrosos o desmesurados, tiende hacia la comprensión y el perdón, nunca hacia el rencor. De su homor (pues La sinagoga de los iconoclastas es esencialmente una obra humorística) no se salva nadie. (2004: 281-283)

Roberto Bolaño (1953-2003), deudor de Schwob, Wilcock y Borges, agarra su pluma en 1996, para escribir La literatura nazi en América, la novela - porque se refiere a la obra como novela - que le da fama después de tantos años de trabajo presistente. Él tampoco utiliza prólogo, pero incluye al final un "Epílogo para monstruos", un índice onomástico, en el que enumera los personajes, revistas y tomos que han aparecido en su novela.

\section{La biografía apócrifa del futuro}

¿De dónde se deriva esta sensación inquietante que presencia el lector a la hora de leer estas obras?

Primero, puede surgir desde el juego entre lo factual y lo ficcional. Mientras Schwob no llena sus obra con elementos eruditos, utiliza fuentes reales, aunque de manera ficcionalizada. Borges ya introduce alusiones a fuentes apócrifas o reales al principio de sus relatos; Bolaño los viste de todos los accesorios de una biografía real (fecha y lugar de nacimiento y de fallecimiento, bibliografía e íncide onomástico final, texto sobrecargado de referencias, datos inútiles); Wilcock se conforma con mencionar posibles coincidencias con la realidad en su nota final, también utiliza biografías concretas en muchos de sus relatos, sus textos a veces incluso parecen ser más historias de una ideología que biografías. Es decir, los autores juegan con esta posición intermedia entre lo factual y lo ficcional, utilizan deliberadamente los instrumentos de la biografía historiográfica para crear un universo misceláneo e inquietante. Es evidente que estas obras no son accessibles desde la realidad objetiva (con la excepción de Schwob, en cuyas obras se puede observar los métodos de reescritura y ficcionalización).

En cuanto a la voz narrativa, se puede observar cierto distanciamiento en comparación con el estilo de Schwob. La sensación probablemente se deriva del estilo sobrecargado por 
referencias aparentemente eruditas y reales. En el caso de Borges, se crea cierto alejamiento, sobre todo, debido al afán burlesco; en el caso de Bolaño y Wilcock, la énfasis recae más en el uso de los elementos característicos de la biografía historiográfica. El narrador es siempre de tercera persona y heterodiegético (con la excepción del último relato en el tomo de Bolaño). La distancia y frialdad de la narración se mezclan con cierto tipo de cercanía como si escucháramos confidencias de un amigo cercano.

Debida a la presencia de un narrador neutral, dice Álvaro Bisama sobre La literatura nazi en América de Bolaño, que "la trampa del libro es la carencia de una voz central" donde el escritor puede realizar "un bestiario donde subyace la literatura como causa y catástrofe, como utopía, a pesar de que el libro corrobore justamente lo contrario, la distopía" (2003: 83). Suárez Hernán y Macías Horas establecen la fractalidad como característica primordial de las biografías apócrifas, aludiendo a un estudio de Ignacio Echevarría, quien utiliza el término "fractalidad" para las reescrituras de propios textos en el caso de Bolaño:

Esta noción de novela total, tan propia de la mitología de la modernidad literaria, parece estar siempre al acecho en la obra de Bolaño. [...] Se manifiesta también en este carácter de obra en marcha, incesante y abarcadora, que adquiere su producción entera observada desde una cierta perspectiva integradora. (Echevarría, 2013: 450)

El principio de los fractales explicaría de igual manera la estructura de la novela: el biografema se repite a una escala mayor en el relato, y el relato igualmente se repite en la novela, como la novela repite la Historia o, en el caso de Schwob, la literatura ya escrita. Así, la fragmentación se llena de sentido, utilizando el método de síntesis de Schwob. El método de inducción tiene a su disposición casi una enciclopedia de falsedades para poder llegar a una conclusión, pero el mundo presentado es como un espejo curvo. El exordio queda eliminado con la excepción de Borges (quien no pudo evitar los prólogos). La ausencia del exordio se explica con los títulos muy directos e inequívocos que definen claramente los temas de los libros.

Asimismo, para Roberto Bolaño es importante el uso de formas clásicas donde puede desmenuzar el nivel mimético, llegando a la "locura filológica" indicada por Celina Manzoni (2002: 45). Pero con el empleo de una narración en apariencia tradicional (sobre todo en sus novelas grandes), crea cierto tipo de extravío y tensión, parecidos a las fuerzas contrapuestas en las novelas de Marcel Schwob, quien produce textos idénticamente llenos de lagunas miméticas.

Mientras Schwob declara la necesidad de ambientar la historia en el tiempo y espacio, en los demás autores llama la atención la falta de descripciones, y la ambientación se limita meramente a la sugerida por el título, que se refiere a algún acontecimiento histórico. Andrés Ibáñez, en su excelente lectura sobre la obra de Bolaño, ha destacado la falta de descripción en sus obras: "Bolaño, por su parte, no describe en absoluto. Su ausencia de descripción es uno de sus rasgos estilísticos más llamativos, parte de su sorpendente disciplina de contención y de "no decir" (2014: s.p.). Y añade que, no obstante, "sus narraciones están llenas de imágenes" (Ibáñez, 2014: s.p.). Esta característica de no describir o describir extratextualmente, por ejemplo, con el título, nos hace volver a la teoría de Schwob sobre la novela de aventuras del futuro. De alguna manera es la acción que gobierna estos relatos. Cuando se agota una historia, la solución será continuar con una nueva historia: de esta manera se manitene la atención lectorial.

Volviendo a la ironía, aludo de nuevo a la afirmación que para poder entender la ironía, el lector debe concebir los conocimientos subyacentes. Roberto Bolaño, en su ensayo "Un paseo por el abismo", dice que la novela total es "la novela que se sumerge en el caos (que es la materia misma de la novela ideal) y que trata de ordenarlo y hacerlo legible" (Bolaño, 2004: 307). Si aplicamos esta afirmación a las biografías ficticias, podemos intuir que, en este caso, 
la ironía no tiene un trasfondo concreto, ya que la novela siempre se emerge desde un caos inicial. Si pensamos en las infamias contra la humanidad descritas por Borges, en el nazismo de Bolaño, en los experimentos inhumanos de Wilcock, todos son delitos universales contra la humanidad, todos estos son delitos de dimensiones universales que quedan impensables e inconcebibles, formando así un caso de acontecimientos imposibles de procesar. De este manera, el tono confidencial del narrador, junto con la ironía, oscilan entre el acercamiento y el alejamiento de los mismos eventos.

En este punto debemos aludir de nuevo al recurso de la inducción, introducido por Marcel Schwob. La inducción que describe sería un método científico, pero con otras bases, es decir, en vez de demostrar algo, se debe intuirlo, y esta intuición tiene la misma validez, siguiendo el ángulo de Schwob. El sistema hegeliano ya no es válido, puesto que el mundo ha demostrado que después de tesis y antítesis no siempre viene la síntesis. La ironía, cuyo significado depende de conocimientos insoportables de la humanidad, pierde su ligereza y gana una faceta más sombría, constituye un abismo, delante del cual todavía disponemos del momento de parar. La relación irónica que se establece en las obras mencionadas de la biografía apócrifa, es una realción de constante acercamiento y de constante alejamiento a la vez. Entre lo ligero y lo doloroso, entre lo factual y lo ficcional, un espejo distorsionador, que a través de su falsedad es capaz de describir mejor estos acontecimientos, que no pueden estar descritos de manera naturalista o realista, sería solamente un catálogo de horrores perdiendo su carácter real.

\section{Conclusiones}

En vez de la desilusión total del realista, estas obras presentan un punto de vista a veces humorístico, a veces doloroso, pero que ha podido encontrar el camino in medias res para describir actos horrendos. El juego constante con ficción y realidad, la modificación constante de la ironía y la voz del narrador constituyen una mezcla interesante e inquietante a la vez, que incita a los filólogos para pensar.

He buscado un hilo conductor para poder describir la dinámica en las novelas de Roberto Bolaño, y he encontrado una hermandad secreta. Creo que Bolaño tiene un papel especial dentro de este grupo, porque la biografía se convierte en base en todas sus novelas y relatos. Andrés Ibáñez ha descubierto este hecho, pero sin mencionar o investigar el subgénero:

El modelo formal básico de Bolaño es la biografía. [...] Este modelo biográfico no es rígido ni en absoluto explícito. A veces se cuenta una vida desde el principio, en otras ocasiones Bolaño se limita a presentarnos un personaje, sus circunstancias, sus amores, sus aficiones, sus manías. Sin embargo, es el modelo principal, y lo que nos ayuda a comprender, quizá, la estructura profunda de la vasta obra de Bolaño: una inmensa colección de vidas. (Ibáñez, 2014: s.p.)

Describe de esta manera el uso de las biografemas, pero para poder entender el significado de estas micro-unidades, se debe conocer la tradición de las biografías apócrifas.

Marcel Schwob ha podido crear un género cuyo significado está ampliándose y formándose con el paso del tiempo, y este hecho significa que es un organismo vivo, que tiene un mensaje válido para nuestra época también. Se podría mencionar más escritores como Alfonso Reyes, Max Aub, Pierre Michon, Christian Garcin o Antonio Tabucchi. He seleccionado los autores siguiendo una cohesión muy fuerte entre sus obras y las referencias que han hecho sobre los otros. No obstante, la investigación de las biografemas y el alejamiento desde el binario de factual y ficticio nos puede llevar a un mejor entendimiento de las obras de autores como Patrick Modiano o W. G. Sebald. 


\section{TEXTOS PRIMARIOS}

BOLAÑO, Roberto (2008): La literatura nazi en América. Barcelona, Seix Barral.

BORGES, Jorge Luis (1954): Historia universal de la infamia. Buenos Aires, Alianza Emece.

SCHWOB, Marcel (2008): Vidas imaginarias. Buenos Aires, Losada.

WILCOCK, Juan Rodolfo (2010): La sinagoga de los iconoclastas. Madrid, Anagrama.

\section{OBRAS CITADAS}

ALAZRAKI, Jaime: "Genesis de un estilo: Historia universal de la infamia", Revista Iberoamericana, № 123-124, Vol. XLIX (1983), 247-261.

BARTHES, Roland (1977): Sade, Loyola, Fourier. Caracas, Monte Ávila. (1989): La cámara lúcida. Madrid, Paidós.

BISAMA, Álvaro (2003): "Todos somos monstruos". Territorios en fuga: estudios críticos sobre la obra de Roberto Bolaño. Ed. Patricia Espinosa. Santiago, Frasis, 79-93.

BOLAÑO, Roberto (2004): Entre paréntesis. Barcelona, Anagrama.

BORGES, Jorges Luis (2005): Obras completas. Barcelona, RBA.

CHAMPION, Pierre (1927): Marcel Schwob et son temps. Paris, Grasset.

CHIRAT, Raymond (2003): La Vie de Marguerite Moreno. Paris, Editions du Rocher.

DOSSET, François (2007): El arte de la biografía: entre historia y ficción. México, D. F., Universidad Iberoamericana.

ECHEVARRÍA, Ignacio (2013): "Bolaño extraterritorial”. Bolaño salvaje. Eds. Paz Soldán y Faverón Patriau. Barcelona, Candaya, 447-461.

GADEN, Élodie: "La Biographie Imaginaire". Publicación online (2005). Enlace: http://www.lettres-et-arts.net/histoire-litteraire-19-21 emes/biographie-imaginaire+89. Última consulta: 10-10-2014.

GARCÍA JURADO, Francisco: "Borges como lector e intermediario entre M. Schwob y A. Tabucchi. El caso de las vidas imaginarias y la historiografía literaria latina", Variaciones Borges: Revista del Centro de Estudios y Documentación Jorge Luis Borges, No 18 (2004), 115-135.

HERNÁNDEZ GUERRERO, María José: "Marcel Schwob cent ans après", Thélème: Revista complutense de estudios franceses, $\mathrm{N}^{\circ} 19$ (2004), 45-55. (Hernández Guerrero, 2004a)

-: "Marcel Schwob: del relato breve a la novela impresionista", Anales de Filología Francesa, No 13 (2004-2005), 189-200. (Hernández Guerrero, 2004b)

—: "El arte de reescritura en Marcel Schwob". Thélème. Revista Complutense de Estudios Franceses, 22 (2007), 125-134.

IBÁÑEZ, Andrés: "Sobre antihéroes y tumbas, o por qué Bolaño es grande", Revista de libros, publicación online (01-08-2014).

Enlace:http://www.revistadelibros.com/ventanas/sobre-antiheroes-y-tumbaso-porque-bolano-es-grande. Última consulta: 10-09-2014.

MANZONI, Celina (2002): "Narrar lo inefable. El juego del doble y los desplazamientos en Estrella distante". Roberto Bolaño: la escritura como tauromaquia. Buenos Aires: Corregidor, 39-50.

RAGUSA, Silvia: "La ironía como manifestación sutil de la argumentación en Vidas imaginarias y en Historia universal de la infamia", Espéculo: Revista de Estudios Literarios, No. 39 (2008), s.p.

Enlace: https://pendientedemigracion.ucm.es/info/especulo/numero39/ironargu.html. Última consulta: 12-10-2014.

SCHWOB, Marcel (2012): El deseo de lo único. Ed. Cristian Crusat. Madrid, Páginas de Espuma. 
SUÁREZ HERNÁN, Carolina y MACÍAS HORAS, Javier: "Herencia narrativa, fragmentación y fractilidad en las biografías infames de Roberto Bolaño y Juan Rodolfo Wilcock", RILCE: Revista de filología hispánica, Vol. 29, № 2 (2013), 495-513.

ZONANA, Víctor Gustavo: "De viris pessimis. Biografias imaginarias de Marcel Schwob, Jorge Luis Borges y Juan Rodolfo Wilcock”, RILCE: Revista de filología hispánica. Vol. 16, No 3 (2000), 673-690.

(C) Kata Varju

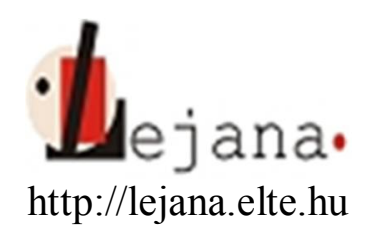

Universidad Eötvös Loránd, Departamento de Español, 1088 Budapest, Múzeum krt. 4/C

Recibido: 16 de febrero de 2015

Aceptado: 13 de octubre de 2015 